В.Г. МОРОЗОВ ${ }^{1}$, д.М.Н., профессор, А.А. ИШМУХАМЕТОВ ${ }^{2,3}$, д.М.Н., профессор, чЛ.-Корр. РАН, Т.К. ДЗАГУРОВА, Д.М.Н., ${ }^{2}$, Е.А. ТКАЧЕНКО ${ }^{2,3}$,

д.М.Н., профессор

1 О0О «Медицинская компания «Гепатолог», Самара

2 Федеральный научный центр исследований и разработки иммунобиологических препаратов им. М.П. Чумакова РАН, ФАНО России, Москва

3 Первый Московский государственный медицинский университет им. И.М. Сеченова Минздрава России

\title{
КЛИНИЧЕСКИЕ ОСОБЕННОСТИ
}

\section{ГЕМОРРАГИЧЕСКОЙ ЛИХОРАДКИ С ПОЧЕЧНЫМ СИНДРОМОМ В РОССИИ}

\begin{abstract}
Геморрагическая лихорадка с почечным синдромом (ГЛПС) - острое вирусное заболевание с аэрогенным механизмом передачи возбудителя, характеризующееся системным поражением мелких сосудов, геморрагическим диатезом, гемодинамическими расстройствами и поражением почек. Возбудителями ГЛПС в России являются 6 хантавирусов: Пуумала, Куркино и Сочи - в европейской части, Хантаан, Амур и Сеул - на Дальнем Востоке. Природными хозяевами хантавирусов и источником заражения людей ГЛПС являются дикие грызуны.

Клиника ГЛПС характеризуется острым началом, цикличным течением, синдромами лихорадки и интоксикации, геморрагическими проявлениями, болями в пояснице и животе и развитием к 4-5 дню острой почечной недостаточности. Характерны лейкоцитоз со сдвигом влево, тромбоцитопения, повышенные показатели мочевины и креатинина, протеинурия, гематурия и снижение относительной плотности мочи. При тяжелом течении развиваются осложнения: кровотечения, инфекционно-токсический шок, отек легких, разрыв почечной капсулы. В зависимости от этиологической обусловленности формы клинического течения ГЛПС имеют выраженные отличия по тяжести и летальности.
\end{abstract}

Ключевые слова: хантавирус, ГЛПС, острая почечная недостаточность, геморрагический синдром, летальность.

\section{CLINICAL MANIFESTATIONS OF HEMORRHAGIC FEVER WITH RENAL SYNDROME IN RUSSIA}

V.G. MOROZOV ${ }^{1}$, MD, Prof., A.A. ISHMUKHAMETOV ${ }^{2,3}$, MD, Prof., corresponding member of the Russian Academy of Sciences, T.K. DZAGUROVA, MD ${ }^{2}$, E.A. TKACHENKO ${ }^{2,3}$, MD, Prof.

${ }^{1}$ LLC Gepatolog Medical Company, Samara

2 M.P. Chumakov's Federal Research Center for Study and Development of Immunobiological Preparations of the RAS, Federal Agency for Scientific Organizations of Russia, Moscow

${ }^{3}$ First Moscow State Medical University named after I.M. Sechenov, MoH RF

Hemorrhagic fever with renal syndrome (HFRS) is an acute viral disease with airborne pathogen transmission, characterized by systemic lesions of small vessels, hemorrhagic diathesis, hemodynamic disorders and kidney failure. In Russia, HFRS causative agents include 6 hantaviruses: Puumala, Kurkino and Sochi in the European part, Hantaan, Amur and Seoul in the Far East. Wild rodents are the natural hosts of hantaviruses and the source of HFRS infection for humans.

HFRS clinical manifestations are acute onset, cyclic course, syndromes of fever and intoxication, hemorrhagic manifestations, pain in the lower back and abdomen, and acute renal failure which develops by day 4-5. Other typical features include leukocytosis with left shift, thrombocytopenia, elevated urea and creatinine, proteinuria, hematuria and decreased relative density of urine. In severe disease, the following complications develop: haemorrhage, toxic shock, pulmonary edema, rupture of renal capsule. Depending on the etiology, clinical forms of HFRS markedly vary by their severity and mortality.

Keywords: hantavirus, HFRS, acute renal failure, hemorrhagic syndrome, mortality.

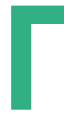

еморрагическая лихорадка с почечным синдромом (ГЛПС) - вирусное заболевание зоонозной природы с аэрогенным механизмом передачи возбудителя, характеризующееся системным поражением мелких сосудов, геморрагическим диатезом, гемодинамическими расстройствами и своеобразным поражением почек (интерстициальный нефрит с развитием острой почечной недостаточности).

Начиная с 1978 г., когда была введена официальная регистрация заболеваемости ГЛПС МЗ РФ, по 2015 г. включительно зарегистрировано более 245 тыс. клинически диагностированных случаев ГлПС. Более 98\% от общего числа случаев ГЛПС выявлено в европейской части страны и около 2\% - в азиатской части, главным образом на Дальнем Востоке.

По данным Роспотребнадзора, только за последние 16 лет, начиная с 2000 г., в 58 субъектах РФ, относящихся к семи федеральным округам, было зарегистрировано 117433 случая ГЛПС, в т. ч. у 2880 детей (2,5\%) в возрасте до 14 лет. 516 случаев (0,5\%) заболевания ГЛПС закончились летальным исходом.

В дальневосточных регионах Российской Федерации ГЛПС вызывается вирусами Хантаан, Амур и Сеул, природными резервуарами для которых являются восточный подвид полевой мыши (Apodemus agrarius mantchuricus), восточноазиатская мышь (Apodemus peninsulae) и серая крыса (Rattus norvegicus) соответственно. На территории европейской части России ГЛПС вызывается вирусами Пуумала, Куркино и Сочи, природными резервуарами для которых являются рыжая полевка (Myodes glareolus), западный подвид полевой мыши (Apodemus agrarius agrarius) и кавказская лесная мышь (Apodemus ponticus) соответственно. Эпидемиологический анализ заболеваемости ГЛПС в России показал, что 97,7\% всех случаев 
ГЛПС этиологически обусловлены вирусом Пуумала, 1,5\% - вирусами Хантаан, Амур, Сеул и 0,8\% - вирусами Куркино и Сочи, что указывает на ведущую этиологическую роль вируса Пуумала в структуре заболеваемости ГЛПС в РФ [1].

Основным путем заражения является воздушно-пылевой, при котором вирус, содержащийся в биологических выделениях зверьков, в виде аэрозоля попадает через верхние дыхательные пути в легкие человека, где условия для его размножения наиболее благоприятны, и затем с кровью переносится в другие органы и ткани. Заражение возможно также через поврежденную кожу при контакте с экскрементами инфицированных грызунов или со слюной в случае покуса зверьком человека. Случаев заражения и передачи возбудителя ГЛПС от человека к человеку за всю историю изучения этой инфекции не зафиксировано.

\section{КЛИНИКА ЗАБОЛЕВАНИЯ}

Сложность клинической диагностики ГЛПС заключается в том, что в первые 3 дня болезни симптоматика не является специфической [2, 3]. Подозрительной на ГлПС можно считать любую острую лихорадку у пациентов, проживающих на территориях природных очагов ГЛПС или посещавших очаги в течение 46 дней до начала заболевания (инкубационный период - от 7 до 46 дней, в среднем - от 2 до 4 нед.). С 4-5-го дня болезни при ее типичном течении и достаточной квалификации медицинского персонала диагностика ГЛПС не вызывает значительных затруднений. Диагноз ГЛПС можно считать вероятным, когда клинические признаки соответствуют характерному течению болезни при наличии эпидемиологического анамнеза. При этом лабораторно подтвержденный случай необязательно должен отвечать клиническому определению случая (атипичные формы).

За 2-3 дня до появления основных симптомов заболевания могут отмечаться продромальные явления в виде незначительной общей слабости и катаральных симптомов. В дальнейшем инфекционный процесс протекает циклично и в своем развитии проходит несколько периодов.

Начальный период (1-3-й день болезни). Как правило, заболевание начинается остро, повышается температура тела, появляются озноб, головная боль, ломота в мышцах и суставах, общая слабость, сухость во рту и жажда. Могут наблюдаться катаральные проявления. У части больных в первые дни болезни на высоте лихорадки и интоксикации появляются тошнота и рвота, иногда жидкий стул до 2-3 раз в сутки без патологических примесей. Патогномоничным для ГлПС является нарушение зрения. Больные отмечают «туман», «сетку перед глазами» (двоение в глазах нетипично). Пациенты имеют характерный внешний вид - у них отмечаются гиперемия кожи лица, шеи, верхней половины туловища, пастозность век, инъекция сосудов склер (рис. 1). Уже в начальном периоде болезни могут появляться геморрагические проявления в виде кровяных корок в носовых ходах, непродолжительные носовые кро-

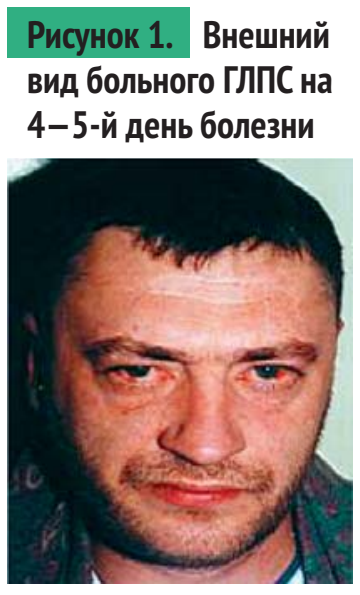

вотечения, единичные петехиальные элементы в над-и подключичных областях, на передней поверхности грудной клетки. На фоне выраженной интоксикации у некоторых больных возможно появление менингеальных симптомов. Регистрируется относительная брадикардия или тахикардия. у части больных на 3-4-й день болезни фиксируется артериальная гипотония с падением АД до неопределяемых значений (OCCH)! Болей в пояснице и животе в начальном периоде, как правило, не наблюдается.

В анализах крови имеются признаки сгущения крови (увеличивается содержание эритроцитов и гемоглобина крови в единице объема), у части пациентов может наблюдаться лейкоцитоз, характерна тромбоцитопения, СОЭ значительно не повышается, а при тяжелом течении даже снижается до 5 мм/4 и менее.

Олигурический период (4-11-й день болезни). К 4-5-му дню от начала заболевания отмечается тенденция к снижению температуры тела, но состояние больных не улучшается. Кардинальным признаком наступления олигурического периода является появление болей в пояснице или/и в животе у большинства пациентов. Интенсивность болей может быть от незначительной до выраженной, купируемой только наркотическими анальгетиками. Отсутствие болевого синдрома или локализация болей только в животе харатеризует атипичное течение болезни. Одновременно снижается диурез, вплоть до анурии, развивается острая почечная недостаточность (ОПН). Появляются тошнота, рвота, при выраженной уремии - икота. Беспокоят общая слабость, бессонница или сонливость, головная боль. Гиперемия кожи лица и верхней половины грудной клетки может сохраняться или сменяться бледностью при значительных проявлениях ОПН. Выраженных отеков не бывает, но пастозность на лице, как правило, сохраняется.

Интенсивность геморрагических проявлений зависит от тяжести течения болезни. Характерными являются кровоизлияния в склеру (симптом «красной вишни») (рис. 2, 3), носовые кровотечения, геморрагическая сыпь на коже, кровоизлияния под кожу, кишечные кровотечения, кровоиз-

\section{Рисунок 3. Субскле- ральные кровоизлия- ния у больной ГЛПС}

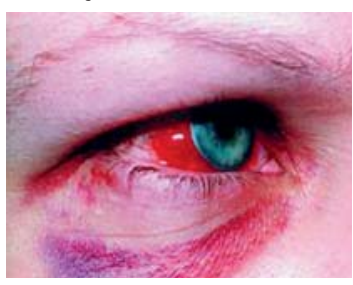

Рисунок 2. Субсклеральные кровоизлияния у больной ГЛПС

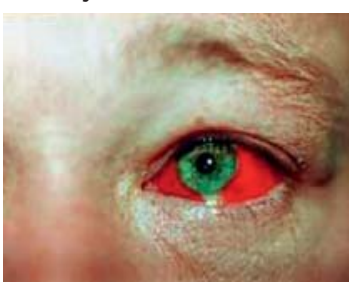


лияния во внутренние органы. У женщин могут быть маточные кровотечения.

Со стороны сердечно-сосудистой системы чаще фиксируются относительная или абсолютная брадикардия. В начале и первой половине олигурического периода чаще регистрируется артериальная гипотензия, во второй половине - артериальная гипертензия. В легких иногда выслушиваются сухие хрипы, при тяжелом течении одышка. Язык суховат, обложен серым или коричневым налетом. При пальпации живота определяются вздутие, локальная или разлитая болезненность, иногда с симптомами раздражения брюшины. У части больных появляется жидкий стул 2-3 раза в сутки без патологических примесей. У некоторых больных может пальпироваться незначительно увеличенная печень. Определяется положительный симптом Пастернацкого, чаще с обеих сторон.

В анализах крови у большинства пациентов (при тяжелом течении - почти у всех больных) в крови наблюдается лейкоцитоз от 9-10 × 10\%/л до $30 \times 10^{9} /$ л и выше. Часто фиксируется сдвиг лейкоцитарной формулы влево. Характерным является появление плазматических клеток в формуле крови, наблюдается тромбоцитопения, которая при тяжелых формах может быть весьма значительной (до 5,0 × 109/л). Увеличение СОЭ незначительное. Концентрации мочевины и креатинина сыворотки крови начинают увеличиваться с начала олигурического периода и достигают своего максимума к 8-9-му дню болезни. Повышение показателей может быть незначительным при легких формах и достигать значений 60,0 ммоль/л для мочевины и 2000,0 мкмоль/л для креатинина при тяжелых формах болезни. При выраженной ОПН повышается концентрация калия, снижаются концентрации натрия и хлора в сыворотке крови. В общем анализе мочи с первого дня олигурии у 90-95\% больных наблюдаются протеинурия (иногда до 33 г/л), у большинства пациентов - микрогематурия, иногда - макрогематурия и цилиндрурия. Патогномоничным для ГЛПС является обнаружение в моче клеток вакуолизированного почечного эпителия. Нередко фиксируется лейкоцитурия. Практически постоянным признаком болезни является снижение к середине олигурического периода относительной плотности мочи (Опл) мочи. Показатели Опл в пробе мочи по Зимницкому могут колебаться на протяжении суток в пределах 1000-1005 (изогипостенурия).

Полиурический период (12-30-й день болезни). Состояние больных улучшается, уменьшается интенсивность болей, увеличивается диурез. У части больных сохраняются общая слабость, жажда, умеренно выраженная артериальная гипертензия, брадикардия, иногда тахикардия, тяжесть или боли в пояснице. Развивается полиурия - максимальный суточный диурез наблюдается к 15-16-му дню болезни и достигает 8-10 л в сутки при тяжелых формах, характерна никтурия. Общий анализ крови нормализуется, снижаются показатели мочевины и креатинина. Патологические изменения в осадке мочи исчезают, но сохраняется изогипостенурия.

Реконвалесцентный период (с 20-30-го дня болезни). Состояние больных существенно улучшается, полностью исчезают тошнота и рвота, больные становятся активными, нормализуется диурез. Данный период в основном характеризуется астено-вегетативными проявлениями, которые могут сохраняться и после выписки больного из стационара. Лабораторные показатели крови приходят в норму, в моче сохраняется изогипостенурия, которая иногда фиксируется несколько месяцев после выписки больного из стационара.

Обычно весь острый период болезни занимает 25-30 дней. У части больных астенический синдром сохраняется от нескольких месяцев до 1 года. Нередко в течение длительного периода времени наблюдаются гипотония, лабильность пульса, одышка при физической нагрузке, снижение полового влечения. Восстановление концентрационной способности почек может затягиваться до нескольких месяцев.

В зависимости от тяжести ГЛПС разделяется на легкую, среднетяжелую и тяжелую формы. При легкой форме интоксикация незначительная, температура тела не выше $38^{\circ} \mathrm{C}$, умеренное уменьшение диуреза, мочевина крови в норме, креатинин - до 130 мкмоль/л, нормоцитоз, незначительная протеинурия, микрогематурия. При среднетяжелой форме интоксикация выражена, температура тела до $39,5^{\circ} \mathrm{C}$, умеренно выраженный геморрагический синдром, олигурия - 300-900 мл в сутки, мочевина 8,5-19 ммоль/л, креатинин - 131-299 мкмоль/л, лейкоцитоз - 8,0-14,0 × 10\%/л, протеинурия, микрогематурия. При тяжелой форме значительная интоксикация, температура тела выше $39,5{ }^{\circ} \mathrm{C}$, геморрагический синдром, уремия, суточный диурез - 200-300 мл, мочевина выше 19 ммоль/л, креатинин - выше 300 мкмоль/л, лейкоцитоз - выше 14,0 × 10\%/л, выраженная протеинурия, микро- или макрогематурия.

Осложнения при ГЛПС: кровотечения и кровоизлияния (рис. 4), инфекционно-токсический шок (ИТШ), острая сердечно-сосудистая недостаточность (ОССН), отек легких, уремическая кома, почечная эклампсия, разрыв почечной капсулы, вторичные бак-
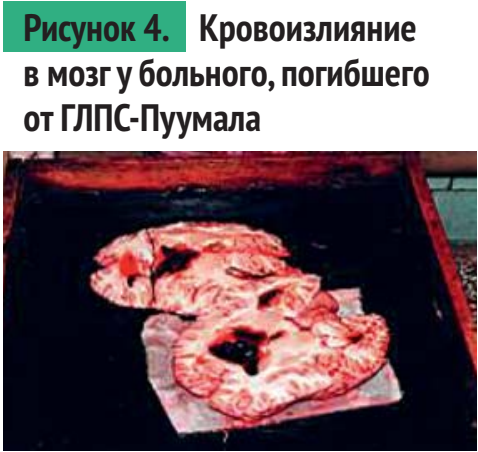
териальные инфекции.

По этиологии заболевание разделяют на ГЛПС, вызываемую вирусами Пуумала (ГЛПС-Пуумала), Хантаан (ГЛПС-Хантаан), Сеул (ГЛПС-Сеул), Амур (ГЛПС-Амур), Куркино (ГЛПС-Куркино), Сочи (ГЛПС-Сочи).Этиологические формы имеют особенности клинического течения [4-9].

ГЛПС-Пуумала - наиболее часто встречающаяся форма заболевания на территории РФ. Примерно у четверти больных ГЛПС-Пуумала протекает в легкой форме, у половины больных - в среднетяжелой и еще у четверти - в тяжелой форме. Геморрагический синдром встречается у 14-20\% пациентов с ГЛПС-Пуумала. Другие клинико-лабораторные проявления достаточно типичны. 


\section{Рисунок 5. Геморрагические проявления (экхимозы) у больного ГЛПС-Хантаан}

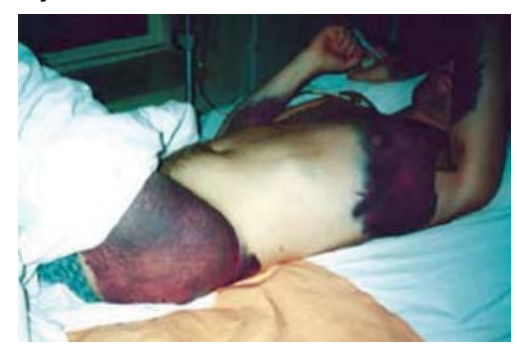

С ущ еств ен н ы м является факт снижения относительной плотности мочи почти у 99,0\% больных. Летальность при ГЛПС-Пуумала составляет 0,4-1\%.

ГлПС-Хантаан регистрируется В дальневосточных регионах РФ. Заболевание протекает тяжелее, чем ГлПС-Пуумала: более чем у трети пациентов заболевание протекает в тяжелой форме, геморрагический синдром наблюдается почти у половины пациентов (рис. 5). Летальность при ГЛПС-Хантаан составляет 5-10\%.

ГЛПС-Амур описана относительно недавно и регистрируется только в дальневосточных очагах. На основании наблюдения за небольшим количеством пациентов можно говорить о схожести клинической картины с ГЛПСХантаан с тенденцией к более частой регистрации абдоминальных симптомов и тяжелых форм болезни.

ГлПС-Сеул регистрируется преимущественно в городских очагах на территории Дальнего Востока РФ. Имеет относительно благоприятное течение, количество тяжелых форм болезни составляет 11-12\%. Геморрагический синдром встречается примерно у каждого десятого пациента. Особенностью данной формы является частое поражение печени. Повышение концентрации билирубина в сыворотке крови обнаруживается почти у каждого пятого больного, повышение активности АЛТ и АСТ - более чем у половины пациентов.

ГЛПС-Куркино регистрируется в очагах, расположенных в регионах Центральной России. Заболевание протекает подобно ГЛПС-Пуумала - тяжелые формы наблюдаются примерно у четверти пациентов. Геморрагические проявления фиксируются относительно редко - у 8-9\% больных. К особенностям клинического течения ГЛПСКуркино следует отнести редкое появление у больных жажды, нарушения зрения, гиперемии лица, ротоглотки и развития полиурии. Лабораторные изменения характеризуются чаще встречающейся лимфопенией и сдвигом лейкоцитарной формулы влево с редким обнаружением плазматических клеток, более значительным увеличением СОЭ и менее выраженным снижением относительной плотности мочи. Летальность при данной форме не превышает 0,5\%.

ГЛПС-Сочи регистрируется в субтропической зоне Краснодарского края и представляет собой наиболее тяжелую форму ГЛПС из регистрируемых к настоящему времени этиологических форм болезни. Более половины пациентов с ГлПС-Сочи переносят заболевание в тяжелой форме и имеют выраженные геморрагические проявления. У большинства больных ГЛПС-Сочи отмечаются признаки поражения желудочно-кишечного тракта в виде болей в животе, тошноты, рвоты и диареи. У каждого десятого пациента отмечаются признаки поражения печени - повышение показателей билирубина и трансаминаз. Летальность при ГЛПС-Сочи составляет 11-14\% (рис. 6).

Следует отметить, что все описанные формы ГлПС могут протекать атипично (безболевой и абдоминальный варианты болезни).

\section{Рисунок 6. Характерный вид почечной паренхимы на разрезе у больной, погибшей от ГЛПС-Сочи}

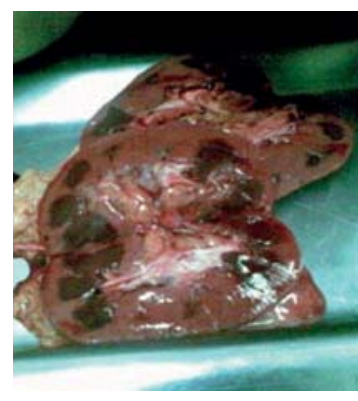

\section{ДИФФЕРЕНЦИАЛЬНАЯ ДИАГНОСТИКА}

ГЛПС дифференцируют с гриппом и другими острыми респираторными инфекциями, сепсисом, лептоспирозом, менингококковой инфекцией, инфекционным мононуклеозом, клещевым энцефалитом и боррелиозом, острыми кишечными инфекциями [9]. Зачастую возникает необходимость проводить дифференциальную диагностику с рядом терапевтических и хирургических заболеваний: пиелонефритом, пневмонией, панкреатитом, аппендицитом, почечной коликой, гломерулонефритом, заболеваниями крови (острый лейкоз), отравлением токсическими веществами. В процессе дифференциальной диагностики следует обращать внимание на следующие обстоятельства: в в первые 3-4 дня болезни следует активно выявлять характерные для ГЛПС симптомы (сухость во рту, жажда, нарушение зрения, субсклеральные гематомы);

- боли в пояснице (и/или в животе) появляются на 3-5-й день болезни, температура тела снижается, но состояние больных ухудшается на фоне развития ОПН;

- при большинстве инфекционных заболеваний, в отличие от ГЛПС, поражение почек (инфекционно-токсическая почка) наблюдается в первые дни болезни на высоте лихорадки;

в в первые 5-6 дней болезни в общем анализе крови характерно увеличение концентрации эритроцитов и гемоглобина за счет сгущения крови без внешних потерь жидкости, в дальнейшем характерны лейкоцитоз (до 25 и более на $10 \%$ /л клеток) со сдвигом лейкоцитарной формулы влево, обнаружение плазматических клеток и тромбоцитопения со значительным снижением числа тромбоцитов в объеме крови при тяжелых формах;

- в общем анализе мочи существенные изменения возникают с 3-4-го дня болезни: протеинурия (от 0,33 до 33 г/л), микро- или макрогематурия, лейкоцитурия (редко значительная), часто цилиндрурия;

- к середине олигурического периода происходит снижение относительной плотности мочи (изогипостенурия), которое может сохраняться несколько месяцев после выписки больного из стационара. 
Применение специфической лабораторной диагностики ГЛПС позволяет выявлять легкие и стертые формы течения инфекции. Легкие формы ГЛПС протекают с 3-4-дневной лихорадкой, умеренным синдромом интоксикации и незначительным поражением почек. Стертые формы ГЛПС представляют собой короткие лихорадочные состояния без каких-либо патогномоничных симптомов. Диагностика таких форм, как правило, осуществляется на основе эпидемиологических и лабораторных серологических данных.

\section{СПЕЦИФИЧЕСКАЯ ЛАБОРАТОРНАЯ ДИАГНОСТИКА}

Заключительный диагноз должен быть верифицирован с помощью лабораторных методов специфической диагностики [6, 8]. Особенно это важно при определении стертых и легких форм заболевания. Для диагностики используют сертифицированные тест-системы, прошедшие регистрацию в России.

$\mathrm{K}$ наиболее широко применяемым методам специфической диагностики ГЛПС относится метод флуоресцирующих антител (МФА) с использованием набора реагентов «Диагностикум ГЛПС культуральный поливалентный для непрямого метода иммунофлюоресценции» производства ФГБНУ «Федеральный научный центр исследований и разработки иммунобиологических препаратов им. М.П. Чумакова РАН». Диагностикум выявляет специфические антитела в сыворотках крови больных людей ко всем известным к настоящему времени вирусам - возбудителям ГЛПС, обеспечивает высокую эффективность выявления больных ГЛПС, независимо от региона и источников заражения, позволяет уже к концу 1-й нед. заболевания выявлять диагностическое нарастание титров специфических антител. Наиболее качественным показателем выявления и этиологической обусловленности заболевания ГЛПС является установление 4- или более кратного нарастания титров специфических антител в парных сыворотках крови больных, взятых в динамике болезни. При обследовании больных с явными клиническими проявлениями ГЛПС и соответствующим эпиданамнезом в 1-2\% случаев антитела к вирусам - возбудителям ГЛПС могут быть не обнаружены. Это свидетельствует о возможном существовании серонегативных форм при этом заболевании.

Кроме МФА для специфической диагностики ГлПС применяется непрямой метод иммуноферментного анализа (ИФА) с использованием «Набора реагентов для иммуноферментного выявления иммуноглобулинов класса $G$ и класса М к хантавирусам в сыворотке (плазме) крови человека» производства ЗАО «Вектор-Бест». Чувствительность непрямого ИФА в формате использования рекомбинантного нуклеокапсидного белка, сорбированного непосредственно на иммунопанель, оказалась несколько ниже на ранних сроках болезни, о чем свидетельствуют более высокие титры флюоресцирующих антител, а также отдельные отрицательные результаты выявления IgM и IgG антител методом ИФА при положительных результатах их выявления непрямым МФА в этих же образцах.

Вирусологическая лабораторная диагностика, направленная на выделение хантавируса от больных ГЛПС, малоэффективна и практически в настоящее время не применяется.

Появление методов индикации генетического материала возбудителя непосредственно в биоматериалах в определенных случаях упростило и ускорило исследования по обнаружению хантавирусов и их типированию. Это особенно актуально при выявлении новых хантавирусных инфекций, принимая во внимание трудности с выделением вируса in vitro. Однако из-за отсутствия коммерческих тест-систем говорить в настоящее время об эффективности применения методов генетического анализа (ПЦР, секвенирование, ПЦР в реальном времени) для специфической диагностики ГЛПС является преждевременным.

\section{ЛЕЧЕНИЕ}

Госпитализация обязательна. Режим в начальном и олигурическом периодах - строгий постельный. Диета - с ограничением белка, без значительного ограничения соли и жидкости [2, 3, 10].

В патогенетическую терапию включаются кристаллоидные растворы внутривенно (раствор глюкозы 5-10\%, раствор натрия хлорида 0,9\% и др.) с контролем концентрации микроэлементов ( $\mathrm{Na}, \mathrm{Cl}, \mathrm{K})$ в сыворотке крови. При этом суточный объем инфузионной терапии не должен превышать суточного количества выделяемой жидкости более чем на 500-700 мл. Мочегонные препараты не назначаются. Коллоидные растворы (реополиглюкин, плазма) применяются только по жизненным показаниям (ИТШ, кровотечения и др.). Назначаются препараты, укрепляющие сосудистую стенку (рутин, аскорбиновая кислота). Целесообразно назначение антигистаминных препаратов (димедрол, пипольфен, супрастин) в среднесуточных дозировках. Глюкокортикоиды (преднизолон) назначаются парентерально в дозе 90-120 мг/сут при тяжелом течении болезни, выраженном геморрагическом синдроме, анурии более 1 сут, олигурии дольше 11-12 дней от начала болезни, ИТШ; в последнем случае суточные дозы определяются состоянием гемодинамики. При тяжелом течении ОПН возможно назначение допамина в/в в области низких доз (100-250 мкг/мин или 1,5-3,5 мкг/Кг/Мин) в течение 6-12 ч под контролем АД (3-4 дня); при развитии ИТШ доза допамина увеличивается. Опубликованы данные о положительном эффекте при тяжелых формах ГЛПС селективного конкурентного антагониста брадикининовых $B_{2}$-рецепторов (икатибант). При ДВС-синдроме в фазу гиперкоагуляции вводят гепарин 1000-5000 ед п/к каждые 4 ч, ингибиторы протеаз (контрикал, гордокс) в/в, в гипокоагуляционную фазу - антиагреганты (дицинон, трентал, курантил). Купирование тяжелых геморрагических проявлений (внутренние и наружные кровотечения и др.) осуществляется по общим правилам.

В качестве симптоматической терапии используют спазмолитики (эуфиллин 2,4\%, но-шпа и др.), обезболивающие препараты (наркотические анальгетики при выраженном болевом синдроме). Антибактериальные средства назначаются в случаях присоединения вторичных бактериальных инфекций. Препараты не должны быть нефроток- 
сичными. Суточные дозы корригируются с учетом выделительной функции почек. В олигурическом периоде возможно проведение индуктотермии на область почек при силе анодного тока 180-200 миллиампер по 30-40 мин 1 р/сут в течение 2-5 дней. При выраженных явлениях ОПН - очистительные клизмы 1-2 р/сут. Лечение осложнений ГЛПС (ИТШ, отек мозга и др.) - патогенетическое, согласно общим принципам. При надрыве почечной капсулы тактика консервативная, при разрыве - хирургическая.

Гемодиализ проводится при анурии более 2 сут, олигурии и отсутствии четкой тенденции к увеличению диуреза к 12-13 дню от начала болезни, гиперкалиемии более 6 ммоль/л. Повышение показателей мочевины и креатинина в сыворотке крови имеет второстепенное значение. Следует помнить, что гемодиализ сопряжен с транспортировкой больного, выполнением различного рода манипуляций и введением гепарина, что на фоне геморрагического синдрома не всегда целесообразно.

Выписка пациентов из стационара осуществляется после исчезновения острых клинических проявлений, нормализации показателей мочевины и креатинина, но не ранее 3-4-х нед. от начала болезни. Умеренная полиурия и изогипостенурия не являются противопоказаниями для выписки.

Прогноз при неосложненном течении благоприятный. Врачам, работающим в очагах ГЛПС, необходимо помнить, что у большинства пациентов заболевание протекает циклично и к 9-11 дню болезни, как правило, наступает полиурический период, за которым следует реконвалесценция. Чрезмерно активные и необоснованные мероприятия в острый период - нередкая причина неблагоприятных исходов при ГЛПС.

У переболевших ГЛПС формируется длительный (вероятно, пожизненный) стойкий иммунитет. Случаев повторного заболевания ГЛПС не отмечалось.

\section{РЕАБИЛИТАЦИЯ}

Реабилитация больных ГЛПС начинается уже в стационаре [11] в периоде реконвалесценции (с 21-25 дня болезни). Постепенно расширяется режим двигательной активности, больные переводятся на палатный режим, а в дальнейшем - на общий режим с возможными прогулками на воздухе.

Лечебная физкультура осуществляется ежедневно, преимущественно в виде дыхательной гимнастики, простых упражнений для рук и ног. Занятия проводятся под контролем методиста ЛФК. Противопоказаны упражнения, связанные с прыжками и резкими изменениями положения туловища.

В периоде реконвалесценции назначается общий стол без употребления острых продуктов и алкоголя. Обильное питье - минеральные воды типа «Ессентуки № 4».

При постинфекционной астении возможно назначение в/в 40\% раствора глюкозы, в/м инъекций кокарбоксилазы 0,05 г, АТФ по 1 мл 1\% раствора. Назначаются адаптогены (настойка лимонника, аралии, заманихи, женьшеня; экстракт элеутерококка, родиолы розовой). Курс лечения составляет 2-3 нед. Показаны антиоксиданты - витамин Е по 50-100 мг/сут, витамин А по 1 драже/сут; аскорбиновая кислота по 0,1 г 3 р/сут на протяжении 3-4 нед.

При неврологических нарушениях назначают витамины $B_{1}$ и $B_{6}$ по 1 мл п/к через день 10-12 дней, никотиновую кислоту в виде 1\%-ного раствора по 1 мл в течение 10-15 дней. Рекомендуются поливитамины внутрь: ундевит, супрадин, центрум и др.

При выраженных признаках гипофизарной недостаточности по согласованию с врачом-эндокринологом могут быть назначены адиуректин, питуитрин.

При поясничном болевом синдроме применяют физиотерапию (индуктотермию, ультразвук, электрофорез с йодом и новокаином, парафиновые и грязевые аппликации).

При миокардиодистрофии лечение должно проводиться с участием терапевта-кардиолога. Назначают рибоксин по 0,2 3 р/сут внутрь или в инъекциях, АТФ по 1 мл 1\% раствор в/м, аскорбиновую кислоту по 0,1-0,2 г 3 р/сут, панангин по 100 мг 3 р/сут.

При почечных проявлениях резидуального синдрома или развитии хронической тубулоинтерстициальной нефропатии (ХТИН) дополнительно назначают трентал, который улучшает микроциркуляцию и активирует обменные процессы в почках, способствует развитию коллатерального кровообращения в почечной ткани. Препарат назначают по 0,1 г 3 р/сут курсами по 2-3 нед.

\section{ЛИТЕРАТУРА}

1. Ткаченко Е.А., Дзагурова Т.К., Ишмухаметов А.А., Морозов В.Г., Городин В.Н., Соцкова С.Е. и др. Геморрагическая лихорадка с почечным синдромом (история, проблемы и перспективы изучения). Эпидемиология и вакцинопрофилактика, 2016, 3: 23-34.

2. Рощупкин В.И., Суздальцев А.А. Геморрагическая лихорадка с почечным синдромом. Саратов: Изд-во Саратовского университета, Куйбышевский филиал, 1990.

3. Сиротин Б.З., Жарский С.Л., Ткаченко Е.А. Геморрагическая лихорадка с почечным синдромом. Хабаровск: Изд-во «РИОТИП», 2002.

4. Морозов В.Г., Коробов Г.Д., Ткаченко Е.А., Иванов А.П., Дзагурова Т.К. и др. Эпидемиологические и молекулярно-генетические характеристики геморрагической лихорадки с почечным синдромом в Самарской области. Казанский медицинский журнал, 2002, 2: 145-38.

5. Слонова Р.А., Ткаченко Е.А., Иванис В.А., Компанец Г.Г., Дзагурова Т.К. Геморрагическая лихорадка с почечным синдромом (современные аспекты экологии, этиологии, эпидемиологии, иммунопатогенеза, диагностики, клиники и лечения). Владивосток: Изд-во ОАО «Примполиграфкомбинат», 2006.

6. Дзагурова Т.К., Ткаченко Е.А., Юничева Ю.В. и др. Обнаружение и клинико-этиологическая характеристика ГЛПС в субтропической зоне Краснодарского края. ЖМЭИ, 2008, 1: 12-16.

7. Ткаченко Е.А., Бернштейн А.Д., Дзагурова Т.К., Морозов В.Г., Слонова Р.А., Иванов Л.И. и др. Актуальные проблемы современного этапа изучения геморрагической лихорадки с почечным синдромом В России. ЖМЭИ, 2013, 1: 51-58.

8. Ткаченко Е.А., Морозов В.Г., Дзагурова Т.К. и др. Этиологические и клинико-эпидемиологические особенности геморрагической лихорадки с почечным синдромом в Краснодарском крае. Эпидемиология и инфекционные болезни, 2016, 1: 22-30.

9. Морозов В.Г., Юничева Ю.В., Брюханов А.Ф., Слюсарева Г.П., Рощупкин В.И., Ткаченко Е.А. и др. Сравнительная характеристика геморрагической лихорадки с почечным синдромом, вызываемой хантавирусами Пуумала и Добрава. Медицинский вестник Северного Кавказа, 2007, 2(6): 38-44.

10. Мухаметдинова Г.А., Фазлыева Р.М., Мустафина В.Х., Дзагурова Т.К. Клинико-эпидемиологическая характеристика геморрагической лихорадки с почечным синдромом в эндемичном регионе. Эпидемиология и инфекционные болезни, 2011, 1: 41-44.

11. Суздальцев А.А., Рощупкин В.И., Морозов В.Г. Реабилитация и диспансеризация больных геморрагической лихорадкой с почечным синдромом. Учебно-методическое пособие, Самара, 1999. 